\title{
Development of Jute Hybrid Composites for use in the Car Panels
}

\author{
Mustafijur Rahman', Vinit Viduran², Kazi Sirajul Islam ${ }^{1 *}$, Adnan Maroof Khan ${ }^{3}$, Nusrat Binta Hossain ${ }^{4}$, \\ Mohammad Forhad Hossain ${ }^{1}$ and Mohammad Abbas Uddin ${ }^{1}$ \\ ${ }^{1}$ Department of Dyes and Chemicals Engineering, Bangladesh University of Textiles, Dhaka, Bangladesh
}

${ }^{2}$ Dolar Gold Belts and Fans Private Limited, West Bengal, India

${ }^{3}$ Department of Apparel Engineering, Bangladesh University of Textiles, Dhaka, Bangladesh

${ }^{4}$ Puls Trading Far East Limited, H\&M Bangladesh Liaison Office, Dhaka, Bangladesh

*Corresponding author: Kazi Sirajul Islam, Department of Dyes and Chemicals Engineering, Bangladesh University of Textiles, Dhaka, Bangladesh.

Received Date: February 17, 2021

Published Date: March 17, 2021

\begin{abstract}
The purpose of this research work is to explore the potential of jute composites to be used in side panels of a car as a lightweight biodegradable substitute to steel and other materials, which will result in better fuel efficiency and maneuvering capabilities. Various tests were carried out to determine the feasibility of using these materials to make car panels. While it has lower tensile and flexural properties than that of carbon fiber material, still it can be replaced as a cheaper alternative to carbon, since carbon is very expensive and scarce. Also, it has higher strength to weight ratio than that of steel while being cheaper than steel, which can make it a plausible option for car manufacturers to look into. But at the same time, there are some issues that are needed to be overcome.
\end{abstract}

Keywords: Jute; Epoxy resin; Composites; Tensile strength; Flexural strength; Car panels

\section{Introduction}

A car, a transport medium, is considered as one of the prime contributors to pollution and global warming due to high carbon emissions. Therefore, the popularity for low emission car such as electric cars increased rapidly. However, electric cars are very expensive comparing the fossil fuel car. There is tremendous pressure on the car industry to lower the carbon emission. One of the major ways to reduce emission is to improve the fuel efficiency of the car, which can be done variety of ways; such as improve the efficiency of engine, reduce the weight of the car panels. Other way could be by substituting synthetic materials by using biodegradable and recyclable materials [1].

Car is mostly made of heavy weight and robust materials such as stainless steel or aluminium (Figure 1). While steel is dominating the industry, brands like Mercedes and Aston Martin usually use aluminum which improves the specific energy absorption capability, allowable strength and is of lower weight and higher tensile strength [1]. Some components of the car like longitudinal front, floors, roofs, firewalls, rear walls, strut tower walls, all have low requirement of tensile properties and can substitute currently popular steel or aluminium with lighter weight natural fiber composites while maintaining the tensile and bending requirements.

Biodegradable and recyclable panel materials, the cars will not harm the environment as they would either mix with the soil or be broken into smaller bits and reused $[2,3]$. In recent decades, interests grew to substitute synthetic composites with green ones 
and few companies like Mercedes Benz, Audi, Mitsubishi, Toyota etc. use green composite. A textile reinforced composite with a combination of polymer matrix are highly useful as it leads to an improvement in the properties of both the phases that intermingle with each other [4-6].

Resin polymers are used in fiber reinforced composites, which when cured bonded with the layer of polymer matrix. When heated, over glass transition temperature, $\mathrm{Tg}$, there is significant change in the mechanical property of the resin, which can be reversed by cooling below $\mathrm{Tg}$. Above the glass transition temperature, stiffness drops sharply, thus decreasing the compressive and shear strength of the composite too [7].

Mercedes- Benz made a composite of jute with epoxy resin for the interior door panels of its E-class cars in 1996. Audi A2 midrange car door panels were made of polyurethane reinforced flax/ sisal composite. Toyota states that it uses the most environment friendly material which is $100 \%$ bioplastics [8]. Green composites were used in making the spare tire cover for RAUM 2003 car model. It was made of sugarcane, sweet potato and was reinforced using kenaf fibers [9]. Car interiors were also made of bamboo, plant- based resin polybutylene succinate (PBS) while floor mats of the Mitsubishi's were made of PLA and nylon fibers. Later, around 2008, soy-based seat foams were used in the Matrix in RAV4 models of the Toyota. In 2010, Ford made its storage bin and inner lids of straw and wheat in the flax crossover, while BMW used prepregnated natural fiber resin mats and a thermoset acrylic copolymer for its lower door panels for its 7 series model of cars [10].

Jute fibers are completely biodegradable. On top of this, a hectare of jute plants, consumes about 15 tons of carbon dioxide while releasing 11 tons of oxygen [11]. In the past, multiple works have been done in understanding and analyzing the qualities of jute fibers and its advantages as a composite. In the year 2000, a study was done on the mechanical performance of jute - epoxy composites. Here jute is reinforced with epoxy resin to make a composite. The method of impregnation should be such as to improve the percentage of fiber loading. In case of this, both untreated and chemically modified slivers have been used to make a composite. When tested for tensile strength, flexural, impact and hardness properties of the composites, the chemically modified specimens showed greater tensile properties while the untreated ones had better flexural properties [12,13] (Figure 1).

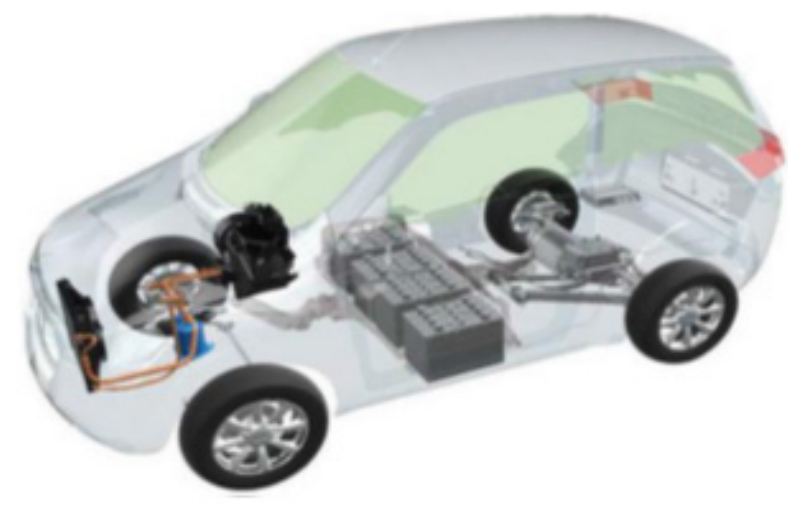

Figure 1: The car body panel of e2o [13].

In this research work, jute yarns have been handing laid and transformed into a composite preventing any form of intersection or overlap as intersecting points could be resin rich and prone to early failure and premature damage. Hence, despite being a labor-intensive process, hand laying can assure homogenous tensile and flexural properties throughout the samples, thus, allowing segregation of application with regards to properties and requirements. This research work is an attempt to make headway into the automotive industry to offer a more ecofriendly alternative to the existing car body materials.

\section{Experimental}

\section{Materials}

Jute yarns with 136.74 twists/m were used. An aluminum tool plate of $50 \mathrm{~cm} \times 50 \mathrm{~cm}$, peel ply, blue mesh fabric, a steel top plate of $35 \times 35 \mathrm{~cm}$, sealant tape, nylon fabric $1.5 \mathrm{~m}$ wide, spiral tubes,
PVC tubes, cotton cloth, nylon bagging film $100 \mathrm{~mm}$ wide, a vacuum pump and connected nozzle, epoxy resin LY113, hardener XB3043, degassing chamber and infuse clamps were used. Moreover, an oven was used to cure the material.

\section{Composite Making}

Laying up: First, a steel plate tool was cleaned using a mould cleaner to prevent contamination. Then, the jute yarns from the prepared cones laid onto the tool plate using hand laying technique (Figure 2). The dimensions set for making the composite panel was $28 \mathrm{~cm} \times 18 \mathrm{~cm}$. The length was kept at $28 \mathrm{~cm}$ in accordance to ASTM D3039 standards which state that the test samples should be of the size $25 \mathrm{~cm}$ in length and $15 \mathrm{~mm}(1.5 \mathrm{~cm})$ in width (Figure 2).

Vacuum Bagging: A $5 \times 5 \mathrm{~cm}$ yellow sealant tape was pressed against all the sides of the plate to remove any loose fiber at the edges ensuring vacuum bagging. Now, sealant tape was put on all 
four sides of the $5 \times 5 \mathrm{~cm}$ tool plate. A piece of blue mesh fabric which cures at or less than $120{ }^{\circ} \mathrm{C}$ used improving resin impregnation. In addition, two pieces of white breathable fabrics $(20 \mathrm{~cm} \mathrm{X} 20 \mathrm{~cm})$ and two pink plastic tubes $(10 \mathrm{~cm} X 25 \mathrm{~cm})$ was used to make a resin trap. Finally, a piece of plastic film $(70 \mathrm{~cm} \mathrm{X} 70 \mathrm{~cm})$ is used to cover the vacuum setup. Finally, two spiral tubes of $15 \mathrm{~cm}$ and $32 \mathrm{~cm}$ length were cut for the tensile and the flexural test specimens respectively.
Also, three PVC tubes of $80 \mathrm{~cm}, 45 \mathrm{~cm}$ and $30 \mathrm{~cm}$ are cut.

Resin trap formation: The plastic tubes are opened, and the folded white breathable fabrics are inserted into plastic sheets (Figure 3). By doing so, when the resin flows out of the tube, the breathable fabric absorbs the resin. Hence, it is called a "resin trap". A valve is used to apply the vacuum properly, which can be divided into 3 parts; Base, sill and head (Figure 3\&4).
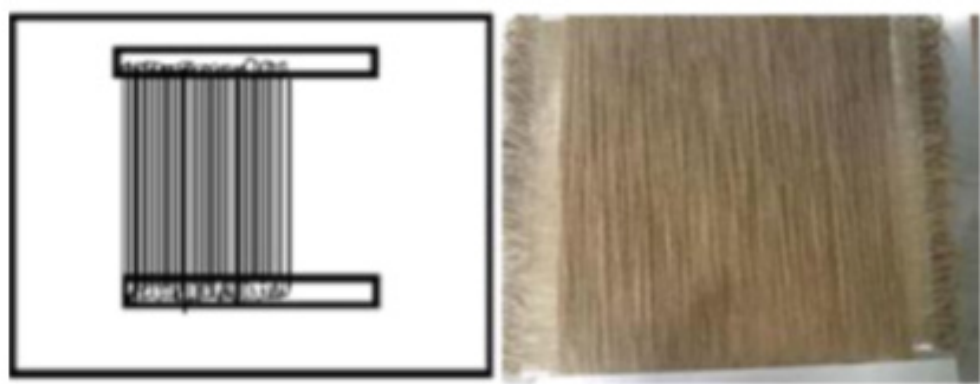

Figure 2: Jute fiber laying up for composite manufacturing.

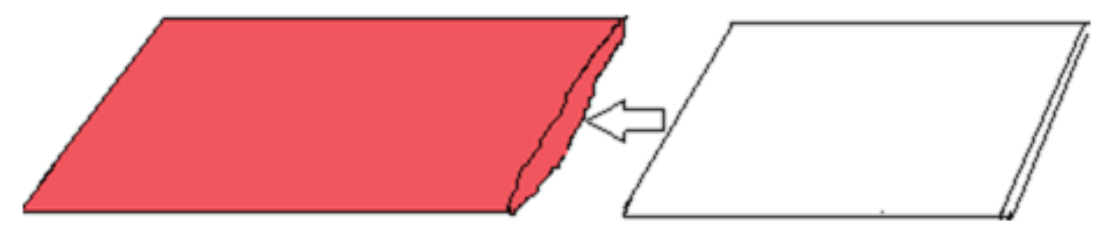

Figure 3: Resin trap- the white cloth being put into the plastic sheet.

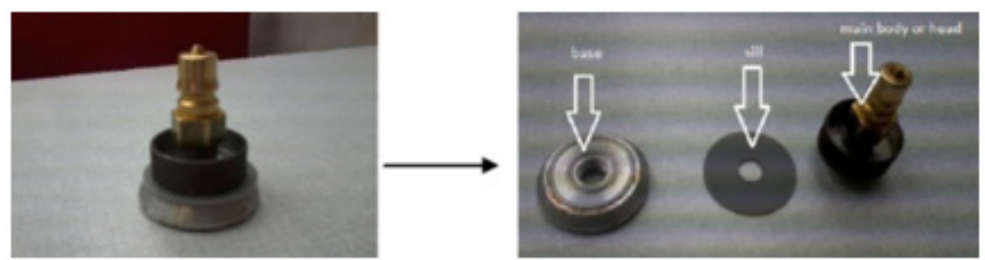

Figure 4: (a) Valve (b) Valve constituents.

The base was the part which goes into the resin trap. The sill was attached to the bottom of the head. The vacuum pump is attached to the valve with a vacuum pipe through a nozzle. The nozzle and the valve connect with the rotor pump in the vacuum pump; the air from inside the setup was pulled forming a vacuum. This applies a
$1 \mathrm{~atm}$ pressure on the material in between the plastic film and tool plate. The meter gauge was checked to see if the vacuum in effect. The spiral tubes are connected to the inlet pipe of the resin trap using cello tape (Figure 5).

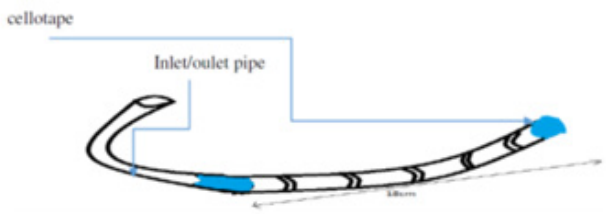

Figure 5: Spiral tubes attached to the pipe. 
These spiral tubes are attached to both sides of the plates, across the longitudinal edges of the lay -up. Then, the green peel fabric was attached on top of the lay-up followed by the blue mesh fabric (Figure 6).
The steel plate is used to give the lay-up a flat surface and also to increase the fiber volume fraction of the composite made. Finally, a vacuum pump is attached to the valve and vacuum is pulled after which it is ready for resin infusion (Figure 7,8).

Figure 6: The stacking sequence before vacuum bagging.

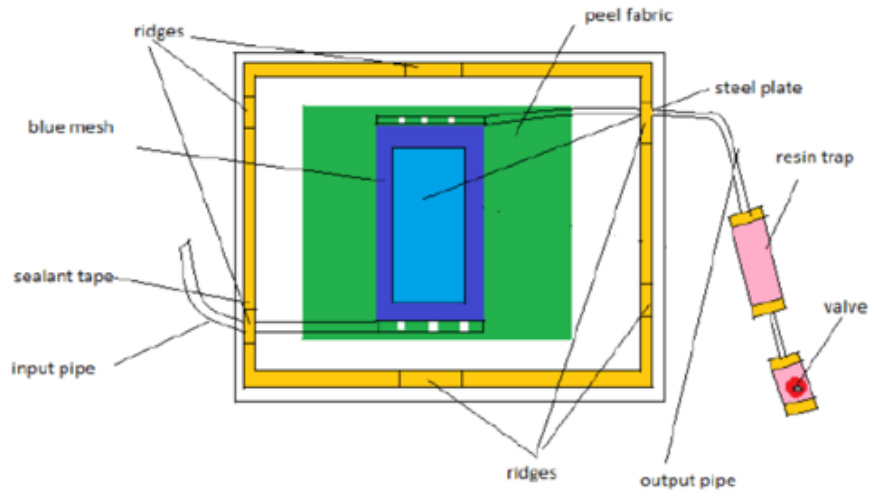

Figure 7: A vacuum filled setup before resin infusion.

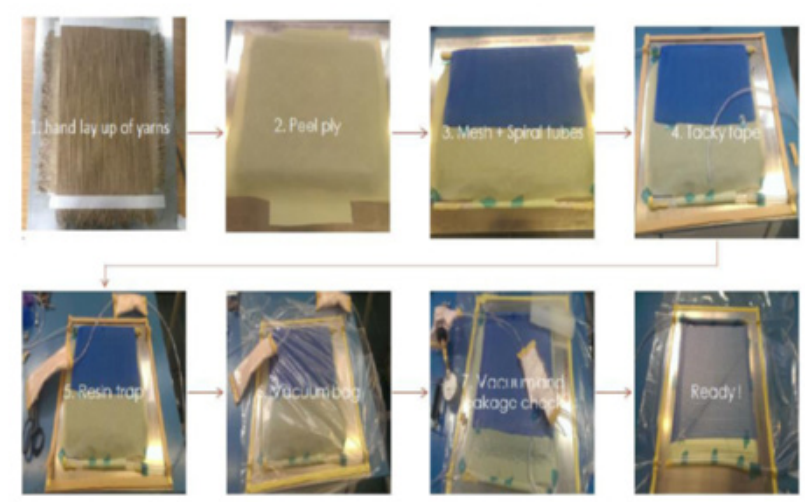

Figure 8: Steps of vacuum bagging.

Resin infusion: The epoxy resin was mixed evenly with a hardener using a wooden stirrer at a ratio of 100:35. The mixture was then put into the degassing chamber to remove the bubbles. At above $40{ }^{\circ} \mathrm{C}$, the mixture slowly started to get cured. A rotor pump pulled the air out of the chamber decreasing the inside pressure. The cup holding the mixture was kept in the chamber for about 40 minutes (Figure 9). 

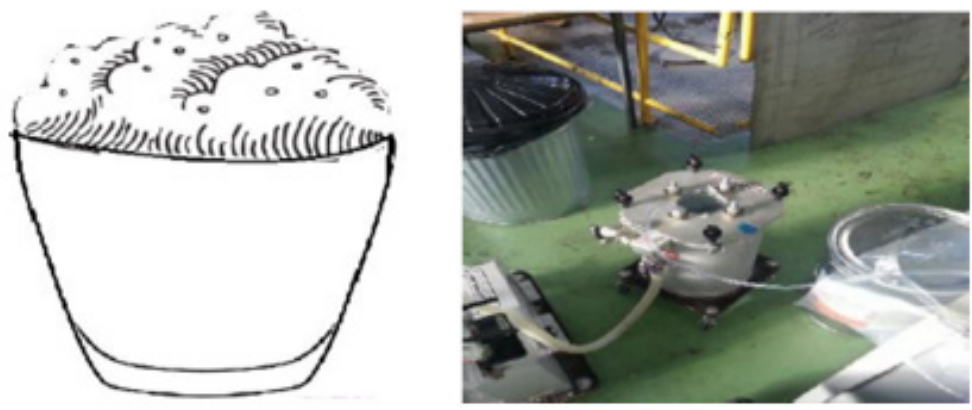

Figure 9: (a) Frothing of the glass containing the mix for infusion. (b) Degassing chamber.

After this, the cup was brought to the tool plate and the sealant tape was removed, followed by dipping the tube into the mixture prepared in the resin cup. The vacuum pump, this time, was to create pressure only to provide better control over the direction of the resin flow (Figure 10)
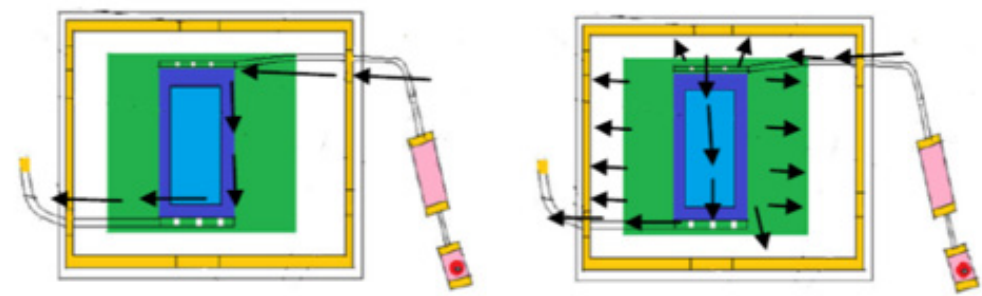

Figure 10: Direction of resin flow (a) with vacuum pump attached (b) without vacuum pump.

Curing: The resin infused setup was taking into the curing chamber. When heat is applied, the viscosity of the resin decreases making it flow further down the tube. The resin trap helps absorb this excess amount of resin preventing any damage. In the first hour, the temperature went up to $80{ }^{\circ} \mathrm{C}$ and stayed for 2 hours, while curing started to take place. Then post curing was carried out where the temperature rose to $120{ }^{\circ} \mathrm{C}$ in 1 hour 15 minutes followed by 6 hours stay at this temperature.

Specimen tensile test: Diamond cutter is used to cut 5 composite samples of $25 \mathrm{~cm} \times 1.5 \mathrm{~cm}$ each as per the D3039 tensile test and 6 samples of $10 \mathrm{~cm} \times 1.3 \mathrm{~cm}$ each for D790 flexural test (Figure 11) (Table 1).

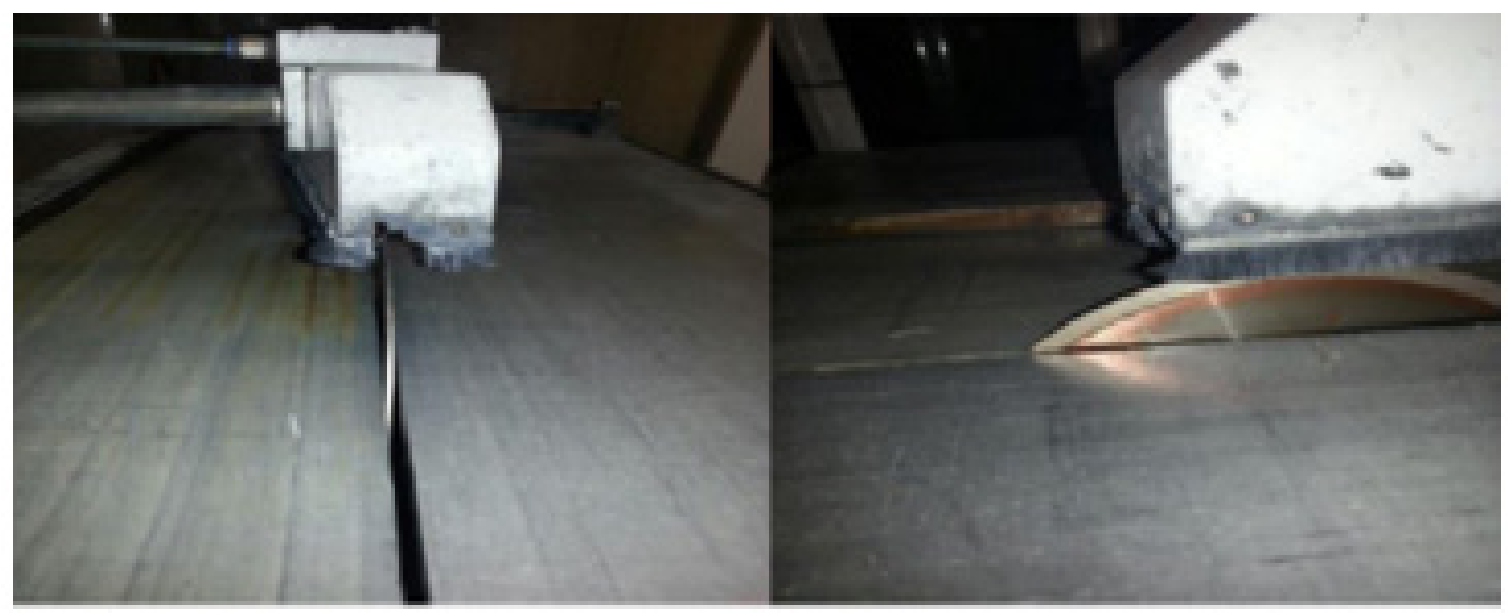

Figure 11: (a) Image of diamond cutter blade (Front View) (c) the blade (Side View). 
Table 1: Overall dimensional data for the specimens of Tensile test in jute composite panels.

\begin{tabular}{|c|c|c|c|c|}
\hline Specimen & $\begin{array}{l}\text { Width } \\
\text { (mm) }\end{array}$ & $\begin{array}{l}\text { Thickness } \\
\text { (mm) }\end{array}$ & $\begin{array}{l}\text { Length } \\
\text { (mm) }\end{array}$ & $\begin{array}{l}\text { Weight } \\
\text { (gm) }\end{array}$ \\
\hline 1 & 14.29 & 3.005 & 24.9 & 13.11 \\
\hline 2 & 15.62 & 3.239 & 24.9 & 14.82 \\
\hline 3 & 14.75 & 3.077 & 24.9 & 13.61 \\
\hline 4 & 15.41 & 3.101 & 24.9 & 14.85 \\
\hline 5 & 15.45 & 3.197 & 24.9 & 14.86 \\
\hline
\end{tabular}

\section{Measurement of tensile strength}

A hydraulic tester with $50 \mathrm{KN}$ load cell was used to perform the tensile tests. An electrical 77 circuit measure the instantaneous load applied along the axis of load. A contact extensometer was used to measure the stress-strain curve and other data. Finally, the width and thickness data of the sample were input into the system and the head speed was set at $2 \mathrm{~mm} /$ minute. The test was initiated, and the recorder automatically calculated all the data and presented a stress strain curve [14].

\section{Measurement of flexural test}

As per ASTM D790-03 flexural test, a round cross sectional head with a diameter of $10 \mathrm{~mm}$ is used. The specimen of $150 \mathrm{~mm}$ x $15 \mathrm{~mm}$ was loaded with a span to depth ratio of $16: 1$. Table 2 shows the overall dimensional data for the specimens of Flexural test (Table 2).

Table 2: Overall dimensional data for the specimens of Flexural test in jute composite panels.

\begin{tabular}{|c|c|c|c|c|}
\hline Specimen & $\begin{array}{c}\text { Width } \\
(\mathbf{m m})\end{array}$ & $\begin{array}{c}\text { Thickness } \\
(\mathbf{m m})\end{array}$ & $\begin{array}{c}\text { Temperature } \\
\left({ }^{\circ} \mathbf{C}\right)\end{array}$ & 22 \\
\hline 1 & 12.17 & 3.4 & 22 & 53 \\
\hline 2 & 12.37 & 3.4 & 22 & 53 \\
\hline 3 & 12.54 & 3.53 & 22 & 53 \\
\hline 4 & 13.03 & 3.22 & 22 & 53 \\
\hline 5 & 13.37 & 3.26 & & 53 \\
\hline
\end{tabular}

Table 3: Equations representing the tensile test data of 5 samples.

\begin{tabular}{|c|c|}
\hline \multicolumn{2}{|c|}{ Equations } \\
\hline $\mathrm{y}=125.47 \mathrm{x}+1.2192 \ldots(1)$ & $\mathrm{y}=140.49 \mathrm{x}+1.7714 \ldots(2)$ \\
\hline $\mathrm{y}=131.67 \mathrm{x}+2.213 \ldots(3)$ & $\mathrm{y}=138.64 \mathrm{x}+2.0971 \ldots(4)$ \\
\hline $\mathrm{y}=141.13 \mathrm{x}+4.1326 \ldots(5)$ & \\
\hline
\end{tabular}

\section{Results and Discussions}

To interpret the tensile modulus, the stress strain data was plot till the point curve obeys Hooke's law. The slope, $m$, from the line equation; $\mathrm{y}=\mathrm{mx}+\mathrm{c}$ represents the young's modulus (tensile modulus) or stiffness (Figure 12\&13). (Table 3).
From the Figure 13, it is observed that, the stiffness is maintained nearly at $135.48 \mathrm{MPa}$. Considering that the stiffness describes how the panel would behave when impact will apply on to it, it can be said that the stiffness limit is much lower than carbon fiber, glass and steel; all of which have the value well above $200 \mathrm{MPa}$ [15] (Figure 14).

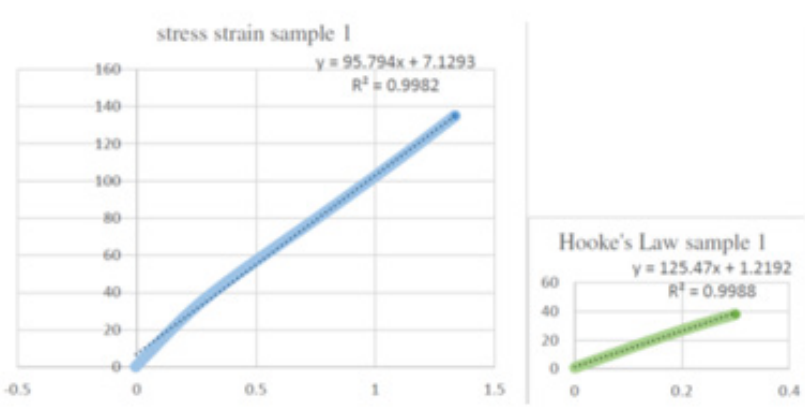

Figure 12: The (a) stress strain and (b) Hooke's law diagrams for sample 1. 


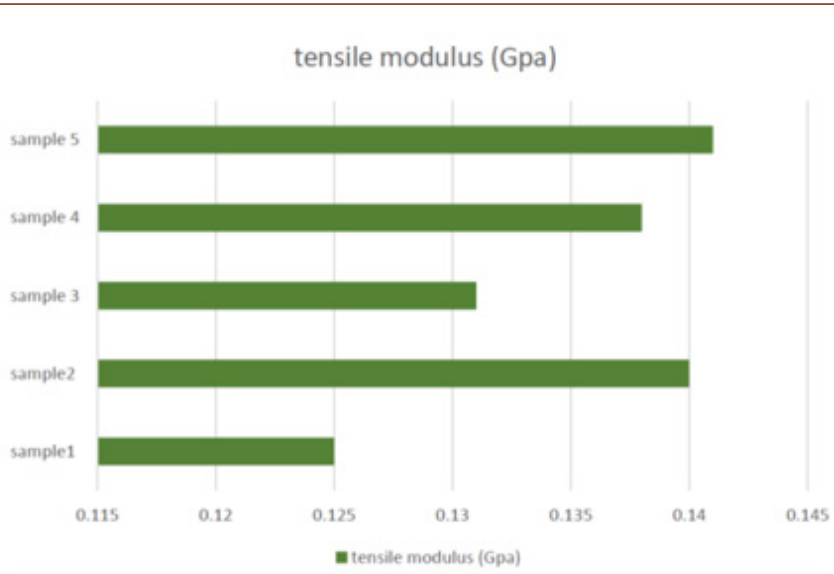

Figure 13: Tensile modulus comparison of all 5 samples.

Figure 14 represents the tensile stress and strain curves for each of the 5 sample. As seen, the curves have little variation from each other, implying that the samples have shown no abnormalities. The yield stress plays important role in understanding the basics of cars and the properties required for making a car panel. Yield stress is the point after which the material goes from elastic deformation to plastic deformation i.e. if the applied stress is higher than the composite's yield point, it will be permanently deformed and will not regain its original shape (Figure 15).

It has been observed in Figure 15 that the stress applied on a composite is higher than the composite's yield stress, thus it means that the composite is permanently deformed and will not regain its original shape. (Figure 16).

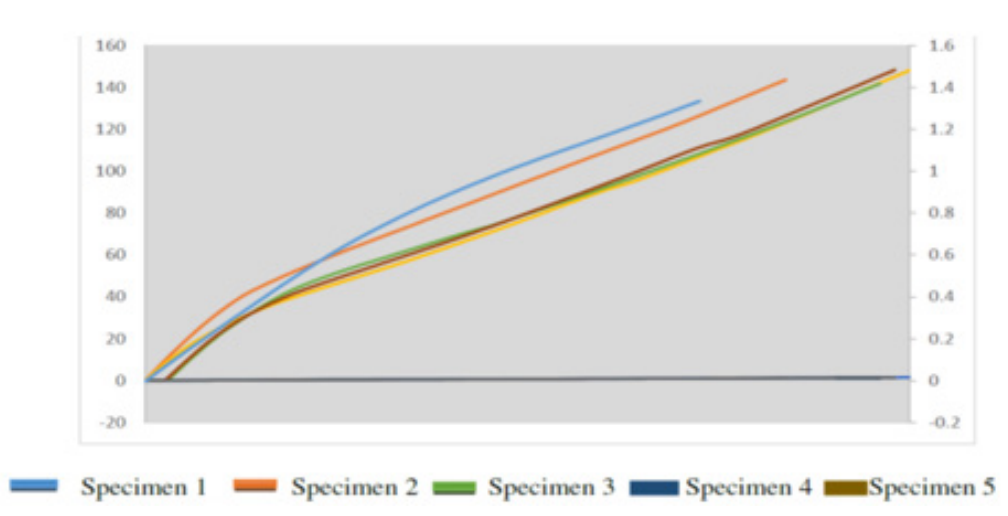

Figure 14: Tensile stress strain curve comparison for 5 Samples.

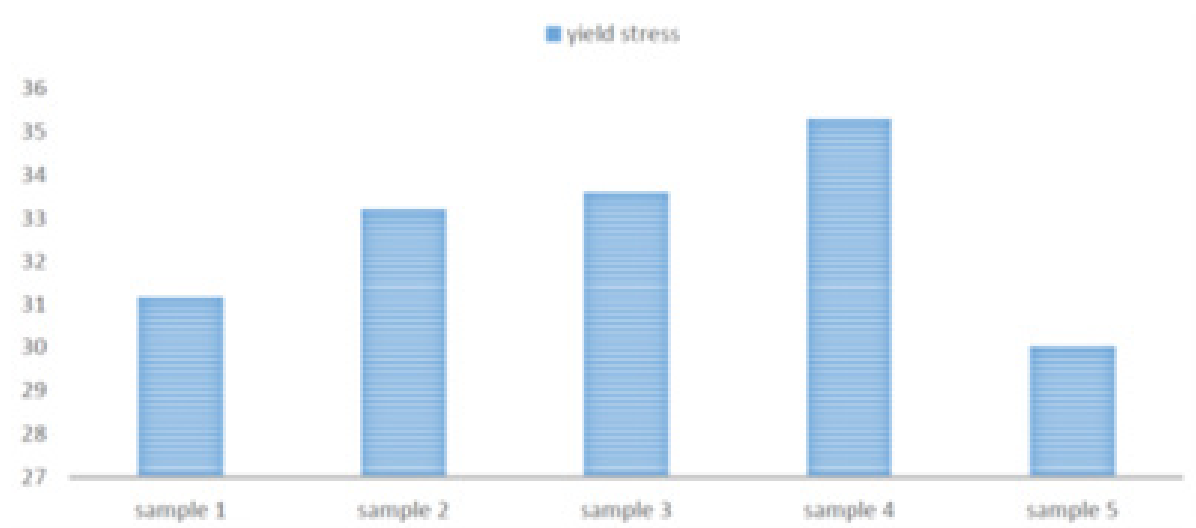

Figure 15: The different yield stresses shown by the composite samples. 
As seen in the Figure 16, the last two specimens show a little higher flexural strength, meaning that there might have been some minor faults while preparing the composite, though the difference is not very high. The little fluctuations seen in the graph in Figure
17 occurs when the force applied on the composite breaks the fibers on the initial layers as the material tends towards failure. It does not imply though that the material has reached failure, it only shows that the material is tending towards it (Figure 17).
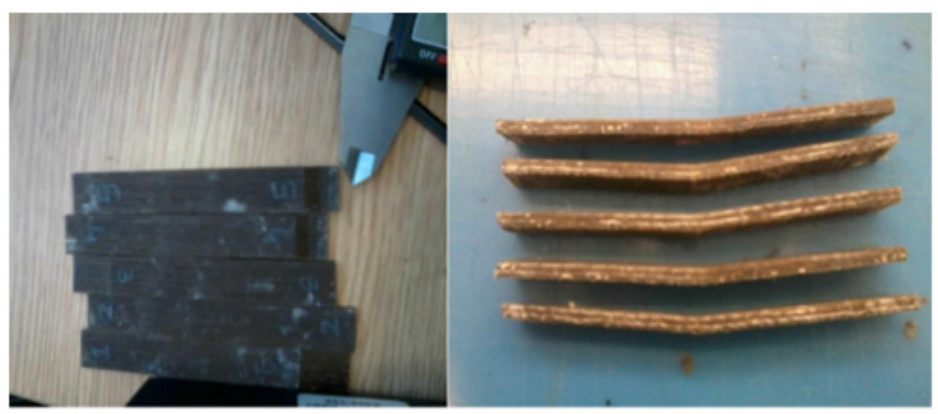

Figure 16: (a) Samples before a flexural test (b) samples after a flexural test.

Specimen 1 to 5
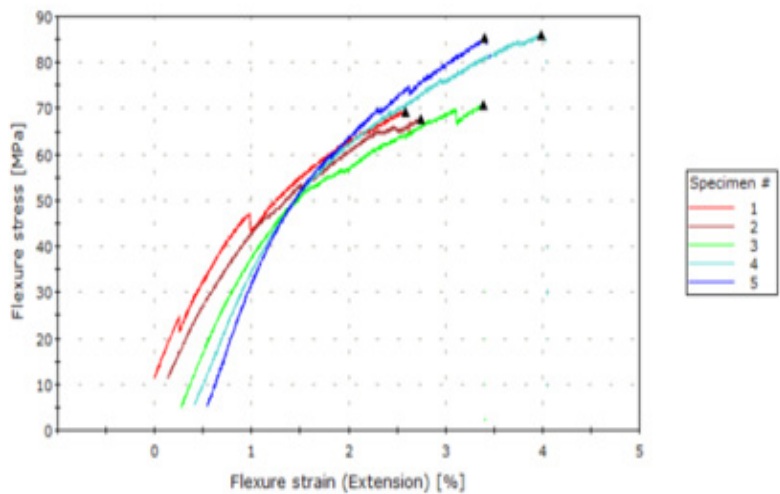

Figure 17: Flexural stress-strain curve of different composites.

Flexural strength is the limit of the composite to withstand flexural stress without failing and is extremely important as it can predict a materials reaction on impact and the amount of bend it forms. Under flexural stress, a material goes through both a tension and compression because of the bending movement. The flexural strength will depend on the material's tensile or compression strength, whichever is lesser in value (Figure 18).

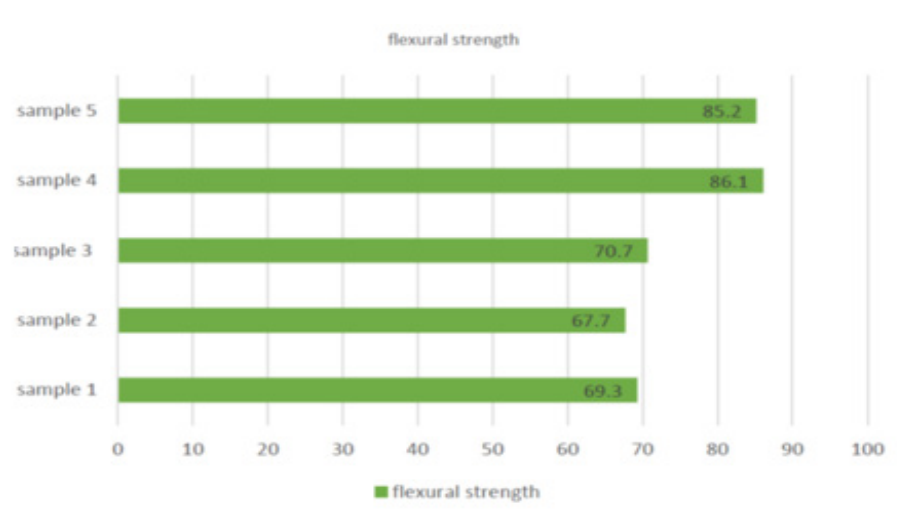

Figure 18: Flexural Strength comparison of all 5 samples. 
The flexural modulus is the ratio of the stress to the strain when flexural deformation takes place. Thus, it represents the materials tendency to bend when force is applied to it (Figure 19).
Having a good flexural modulus (Figure 19) is very important since even if the material does not fail when subjects to high impact, it may bend much to cause damages to the passengers of the car (Figure 20).

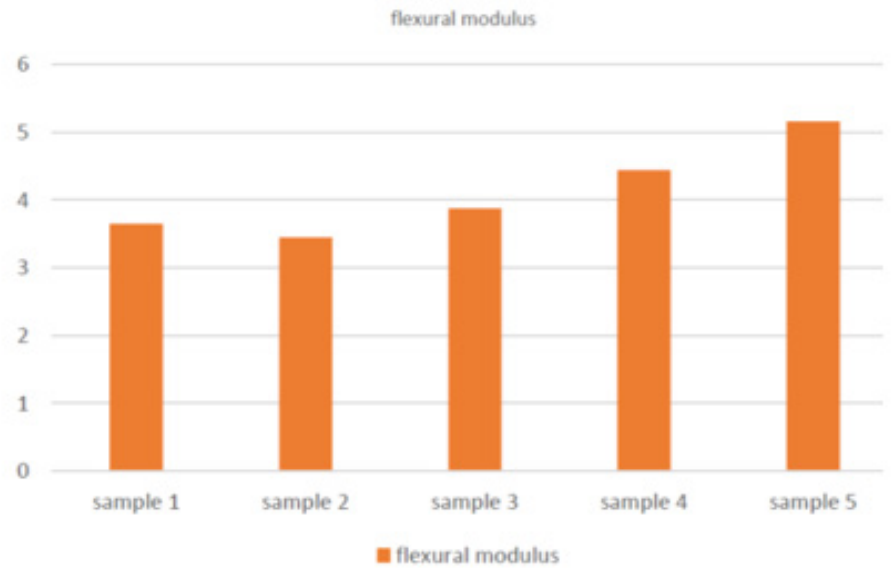

Figure 19: Flexural modulus on different composites.

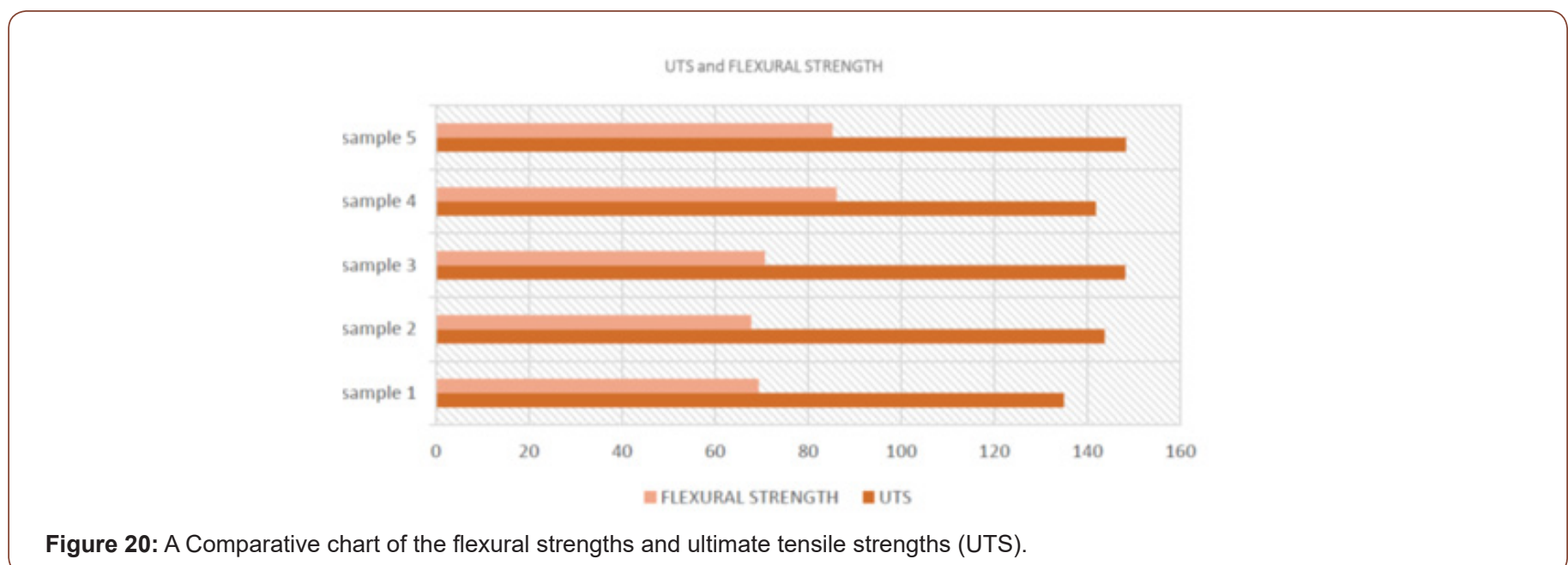

As it can be seen from the tables and graph above, the tensile strength and flexural strength vary a little from each other in every case. This can be attributed to a lot of factors as the following: Non-uniform blending of jute: Different grades of fibers are blend in together to form a batch. Naturally, yarn made of various proportions of the different grades of jute intertwined each other, leads to the formation of varied properties in different parts of the cone.

Non-uniform twisting: Different sections of the yarn have different twist levels. This may lead to variation in tensile values. Since these are natural fibers with high z-direction twist, they do not settle down easily. This prevents a uniform twist formation and some areas have larger yarn diameter than others. Again, thinner the yarns are, higher the number of twists and higher tension on the yarns in those areas. Fiber alignment: Since the lay-up was done using hand, and not with any machine, some yarns, approximately 2 yarns/ layer, lose tension or alignment, which might create varied data while testing. Differences in dimensions: Since the sample was cut using manual machine, the dimensions of the samples differed slightly from each other. Though, they conferred to the standards, still it might cause the differences in data. Comparison of the weight to strength ratio in Figure 21 shows that the weight to strength ratio of composite is higher than mild steel. This means that composite materials have less weight and more strength, which could be appropriate for car panels (Figure 21).

Different parts of the car require different amounts of yield stress to maintain its safety and security. While some parts of the car play an extremely important role, others are far less affected on the event of a crash. The strength and stiffness requirement for floors and roofs are far lower than the rest of the car. Also, the 
sidewalls do not require high strength and stiffness, while in areas such as the rear wall, though the strength requirement is low, the stiffness requirement is high. In areas like these, the use of lower weight materials could be highly useful. The Figure 22 would justify the use of the composites on these specific parts [16] (Figure 22).

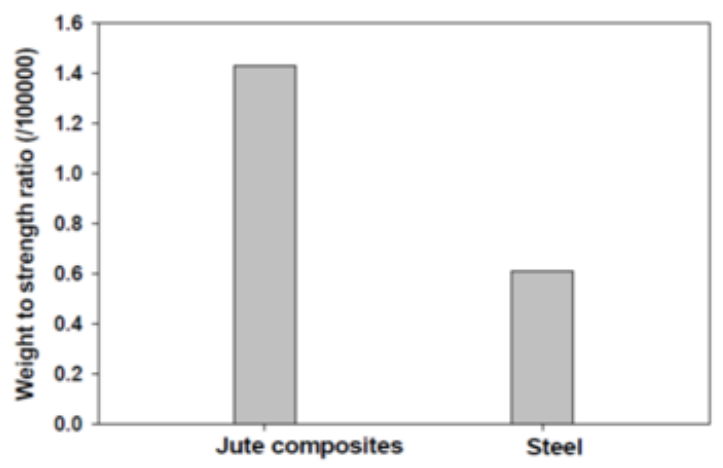

Figure 21: Comparison of the weight to strength ratio.

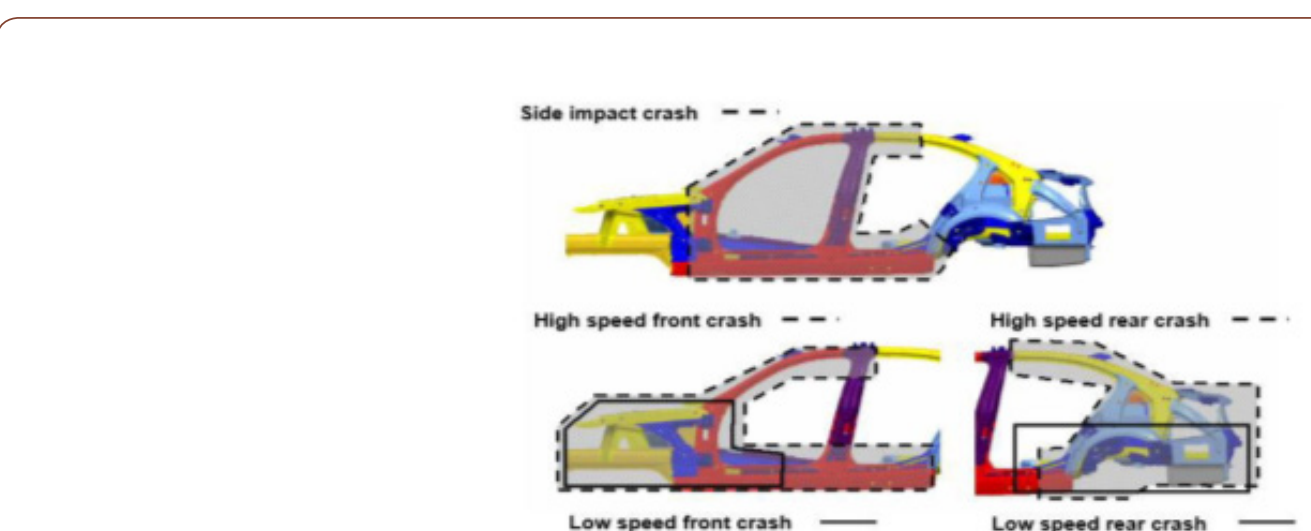

Figure 22: Areas of a car affected when a crash occurs [16].

As the Figure 22 shows, only in cases of high-speed crashes, the roof and floor are damaged and also the magnitude of the damage is far lower than the rest parts. While jute composites are not recommended to be used as a direct alternative to the currently popular mild steel panels, it can be used as internal body substitutes for multiple reasons. Jute composite having good flexural properties for an internal car panel, would help prevent the steel panel from bending while simultaneously preventing the excess impact, which has channeled through the steel panel, to transfer completely to the individual utilizing the car. Thus, the jute composite's flexural and tensile properties will be extremely useful.

Lightweight design is another important aspect to consider. This will reduce the fuel consumption, since one third of the $\mathrm{CO} 2$ emissions occur from engine factors. Moreover, lightweight design will reduce aerodynamic drag, results in better handling and car movement. Furthermore, rolling resistance will be reduced slightly. This helps in improving the speed of the car. Other additional advantages such as optimization of auxiliary aggregates will help to cause less emission from vehicles and improve vehicle efficiency. Again, most people buy cars considering its driving dynamics, so, the lightweight design will raise the brand value [17].
Steel is far heavier than jute composites. While $118.24 \mathrm{~mm} 2$ of jute composite weighs $0.4414 \mathrm{~N}$, the same area of mild steel weighs $3.375 \mathrm{~N}$. This means steel made cars are bulkier, slower and less fuel efficient. Jute composites could help improve movement, handling, fuel efficiency, carbon dioxide emission, and also speed of the car. Conversely, though steel production is very cheap, but requires high initial investment, especially, since steel has to be stamped out. Jute composite needs less initial capital with very low production cost, hence cheaper for the manufacturing company. Moreover, jute has a higher strength to weight ratio than that of steel. So, jute composite is a better alternative to steel especially to a certain extent.

\section{Conclusion}

This research work focused on the stiffness and the flexural data of a jute reinforced epoxy composite. An important finding includes that, while this particular jute composite cannot completely replace existing materials being used, such as steel and in some cases aluminium, but for a certain extent it can be used in cars as a replacement of these materials in some specific areas. Yet a few other important tests such as an impact test and dent resistance test is recommended to determine the use of jute composites and confirm its ability as a potential future replacement. Also, different 
treatments can be used in jute to improve its strength and making it stronger than it is now. Also, it can be sandwiched between layers of aluminium and tested for tensile, flexural and impact data followed by a dent resistance test. This is expected to yield values that could comfortably replace mild steel materials being used in cars and also make the cars lighter and easier to run while simultaneously making them environmentally friendly. Also, the use of natural resins can be looked into for the future. This would help improve the biodegradability of the composite. Soya resin can be one of the resins that can be looked into in the future. Emphasis can be given to manufacture jute composites as it shows great potential as a future substitute to heavier materials being used for making car panels. This study has demonstrated all the objectives and come out with some favorable outcomes and also some drawbacks that will have to be looked into in the future as the technology grows.

\section{Disclosure Statement}

No potential.

\section{Acknowledgement}

None.

\section{Conflict of Interest}

There is no conflict of interest

\section{References}

1. Camberg AA, Tröster T (2018) Optimization-based material design of tailored stacked hybrids for further improvement in lightweight car body structures. In Proc Hybrid 2018, 3rd Int Conf Hybrid Mat \& Struct (Eds. JM Hausmann, M Siebert, A von Hehl), Bremen, Germany, pp. 1819.

2. Bastioli C (2020) Handbook of biodegradable polymers. Walter de Gruyter GmbH \& Co KG.

3. Mishra HK, Dash BN, Tripathy SS, Padhi BN (2000) A study on mechanical performance of jute-epoxy composites. Polymer-Plastics Technology and Engineering 39(1): 187-198.
4. Solemanifar (2014) Damage Tolerance of Composites Containing Hybrid (Carbon-Innegra $^{\mathrm{TM}}$ ) Fiber Reinforcements, Manchester.

5. Warren CD (2011) Low cost carbon fiber overview. Oak Ridge National Laboratory, Oak Ridge, Tennessee.

6. Gassan J (2002) A study of fibre and interface parameters affecting the fatigue behaviour of natural fibre composites. Composites part A: applied science and manufacturing 33(3): 369-374.

7. Hossain MR, Islam MA, Van Vuurea A Verpoest I (2013) Tensile behavior of environment friendly jute epoxy laminated composite. Procedia Engineering 56: 782-788.

8. Sanjay MR, Arpitha GR, Naik LL, Gopalakrishna K, Yogesha B (2016) Applications of natural fibers and its composites: An overview. Natural Resources 7(3): 108-114.

9. Akampumuza O, Wambua PM, Ahmed A, Li W, Qin XH (2017) Review of the applications of biocomposites in the automotive industry. Polymer Composites 38(11): 2553-2569.

10. Koronis G, Silva A, Fontul M (2013) Green composites: A review of adequate materials for automotive applications. Composites Part B: Engineering 44(1): 120-127.

11. S Shaktivel, OP Lakshmanan, A Zaid Hamsa, SD Kiruthika, E Rajadurai (2012) Application of Jute and Its overviews.

12. Wang H, Memon H, AM Hassan E, Miah M, Ali M (2019) Effect of jute fiber modification on mechanical properties of jute fiber composite. Materials, 12(8): 1226

13. Arora S, Patel J, Ubeja S (2015) Event study on stock prices of Mahindra and Mahindra Ltd.: A study on launch of Mahindra e2o. FIIB Business Review 4(4): 71-77

14. Çevik G, Gürbüz R (2013) Evaluation of fatigue performance of a fillet rolled diesel engine crankshaft. Engineering Failure Analysis 27: 250261.

15. Fiorelli J, Dias AA (2003) Analysis of the strength and stiffness of timber beams reinforced with carbon fiber and glass fiber. SciELO, pp. 14391516

16. European aluminum association (2010) Stiffness Relevance and Strength Relevance in Crash of Car Body Components.

17. Kopeliovich D (2017) Flexural tests of ceramics. Knowledge source on materials engineering. 